\title{
SONOGRAPHIC GRADING OF RENAL CORTICAL ECHOGENICITY AND RAISED SERUM CREATININE IN PATIENTS WITH CHRONIC KIDNEY DISEASE
}

\author{
Arvinder Singh ${ }^{1}$, Kamlesh Gupta², Ramesh Chander 3 , Mayur Vira ${ }^{4}$ \\ ${ }^{1}$ Associate Professor, Department of Radiodiagnosis, Government Medical College, Amritsar. \\ 2Professor, Department of Radiodiagnosis, SGRDIMSAR, Amritsar. \\ ${ }_{3}^{3}$ Associate Professor, Department of Radiodiagnosis, Government Medical College, Amritsar. \\ 4Junior Resident, Department of Radiodiagnosis, Government Medical College, Amritsar.
}

\begin{tabular}{l} 
ABSTRACT \\
\hline BACKGROUND \\
Chronic Kidney Disease (CKD) is a worldwide public health problem and the world's 12th commonest cause of mortality and \\
17th cause of morbidity. The approximate prevalence of CKD in India is 800 with an incidence of about 150-200 per million \\
population. The most common cause of CKD is diabetic nephropathy.
\end{tabular}

\section{PURPOSE OF STUDY}

The purpose was to study various renal sonographic changes in patients with chronic kidney disease and to correlate renal length, parenchymal thickness, cortical thickness and echogenicity of the kidney with serum creatinine levels.

\section{MATERIAL AND METHODS}

The study was conducted on hundred patients in the Department of Radiodiagnosis and Imaging, Government Medical College, Amritsar, from August 2013 to October 2015. Patients were subjected to sonographic examination on Philips Envisor C Ultrasound machine/Toshiba ultrasound machine model-SSA. 510A/Esaote ultrasound machines using curvilinear probe of $3.5 \mathrm{MHz}-5 \mathrm{MHz}$ or linear high frequency probe 7-12 MHz. Ultrasound of kidneys for renal length, parenchymal thickness, cortical thickness and cortical echogenicity was performed. The mean values of both kidneys were calculated from length, parenchymal thickness and cortical echogenicity. These parameters were compared with serum creatinine. Statistical analysis was performed using one-way ANOVA.

\section{RESULTS AND CONCLUSIONS}

The grade of renal disease was determined by cortical echogenicity with Grade 1 mild form, Grade 2 moderate and Grade 3 severe form and Grade 4 as end-stage renal disease. The mean serum creatinine was $2.87 \mathrm{mg} / \mathrm{dL}$ for Grade 1, $3.27 \mathrm{mg} / \mathrm{dL}$ for Grade 2, $4.3 \mathrm{mg} / \mathrm{dL}$ for Grade 3 and $5.8 \mathrm{mg} / \mathrm{dL}$ for Grade 4. No correlation was observed between renal length, parenchymal thickness and cortical thickness with serum creatinine levels. The grading of renal echogenicity on sonography correlated well with serum creatinine in CKD than any other sonographic parameters with a statistically significant positive correlation $(\mathrm{P}<0.001)$.

\section{KEYWORDS}

Chronic Kidney Disease, Renal Cortical Echogenicity, Serum Creatinine.

HOW TO CITE THIS ARTICLE: Singh A, Gupta K, Chander R, et al. Sonographic grading of renal cortical echogenicity and raised serum creatinine in patients with chronic kidney disease. J. Evolution Med. Dent. Sci. 2016;5(38):2279-2286, DOI: $10.14260 /$ jemds/2016/530

\section{INTRODUCTION}

Chronic Kidney Disease (CKD) is a worldwide public health problem, both for the number of patients and cost of treatment involved. Globally, CKD is the $12^{\text {th }}$ cause of death and the $17^{\text {th }}$ cause of disability, respectively. This is an underestimate as patients with CKD are more likely to die of cardiovascular disease than to reach End-Stage Renal Disease (ESRD). ${ }^{1}$ The approximate prevalence of CKD in India is 800 per million population (pmp) and the incidence of ESRD is 150-200 per million population. The commonest cause of CKD is diabetic nephropathy. ${ }^{2}$

Financial or Other, Competing Interest: None.

Submission 02-03-2016, Peer Review 30-03-2016,

Acceptance 04-04-2016, Published 10-05-2016.

Corresponding Author:

Dr. Arvinder Singh,

\#316-A, Moon Ave,

Amritsar.

E-mail:arvinderdr@rediffmail.com

DOI: $10.14260 /$ jemds $/ 2016 / 530$

\section{CKD is Defined as}

1. Kidney damage $\geq 3$ months, as defined by structural or functional abnormalities of the kidney with or without decreasing GFR, manifest by either: pathological abnormalities or markers of kidney damage including abnormalities in the composition of blood or urine or abnormalities in the imaging tests.

2. GFR $<60 \mathrm{~mL} / \mathrm{min} / 1.73 \mathrm{~m}^{2}$ for $\geq 3$ months with or without kidney damage. ${ }^{3}$

Renal ultrasound is simple, inexpensive and can be done at the bedside to provide the clinician with important anatomical details of the kidneys with a low inter-observer variability. 4 The safety of the diagnostic procedure using ultrasound is well established. 5

\section{In the Clinical Practice, Ultrasonography is used in the Initial Evaluation of CKD Patients for three Major Reasons as follows}

1. To rule out potentially reversible causes (e.g., collecting system dilatation). 
2. To make a decision about a possible renal biopsy in cases where US fails to define the CKD aetiology.

3. To obtain renal measurements as a prognostic factor. Such measurements are important since in most cases CKD leads to a common final-stage condition characterized by small kidneys, cortical and parenchymal thinning (indicating atrophy) and hyperechogenicity indicating sclerosis and fibrosis (small, dense, echogenic kidneys); such findings indicate disease irreversibility and poor prognosis. ${ }^{6}$

The measurement of serum creatinine has been the traditional approach to assessing CKD. eGFR derived from formulas such as the Modification of Diet in Renal Disease (MDRD) equation is superior to serum creatinine alone in the diagnosis of CKD. However, busy clinicians are unlikely to routinely calculate eGFR from serum creatinine for all of their older patients. ${ }^{7}$

\section{MATERIAL AND METHODS}

Hundred patients, clinically diagnosed with chronic kidney disease (GFR $<60 / \mathrm{mL} / \mathrm{min}$ calculated by using CockcroftGault equation, for three months or more) above the age of 18 years, referred to the Department of Radiodiagnosis and Imaging, Government Medical College, Amritsar, from August 2013 to October 2015. The patient was made to lie supine on the examination table.

The ultrasound coupling gel was applied to the abdomen so as to remove air between the abdominal skin and the transducer. Patients were subjected to sonographic examination on Philips Envisor C ultrasound machine/Toshiba ultrasound machine model-SSA. $510 \mathrm{~A} /$ Esaote ultrasound machines using curvilinear probe of $3.5 \mathrm{MHz}-5 \mathrm{MHz}$ or linear high frequency probe 7-12 MHz. Longitudinal, transverse and oblique views were taken.

The exclusion criteria were the patients on haemodialysis, peritoneal dialysis, renal transplant patients, patients with hepatic diseases diagnosed on ultrasonography and renal tumours (Both Primary and Secondaries).

The detailed history from patients regarding age, duration of diabetes mellitus if diabetic, duration of hypertension if hypertensive, other causes of chronic renal failure and treatment history. The most recent serum creatinine values were noted. After taking the informed consent of the patient for investigation, each patient was subjected to ultrasound of the abdomen for kidneys and liver. Low tissue harmonic imaging was applied to visualize the liver and kidney echogenicities. A manual method of adjusting the gain and Time Gain Compensation (TGC) was used.

Renal lengths were measured as the greatest pole to pole distance in the sagittal plane (Figure 5). Renal parenchymal thickness was measured from the renal hilum to the maximum convex border of the lateral renal margin (Figure 6). Renal cortical thickness was measured over a medullary pyramid, perpendicular to the capsule as the shortest distance from the base of the medullary pyramid to renal capsule (Figure 7). In every case, the mean values of the right and left renal longitudinal size, parenchymal thickness and cortical thickness were calculated.

Renal cortical echogenicity and cortico-medullary differentiation was evaluated. Renal cortical echogenicity was compared and graded with the echogenicity of the liver and renal medulla with Grade 0: Normal echogenicity less than that of the liver with maintained cortico-medullary differentiation.

Grade 1: Echogenicity the same as that of the liver with maintained cortico-medullary differentiation (Figure 8). Grade 2: Echogenicity greater than that of the liver with maintained cortico-medullary differentiation (Figure 9). Grade 3: Echogenicity greater than that of the liver with poorly maintained cortico-medullary differentiation (Figure 10). Grade 4: Echogenicity greater than that of the liver with a loss of cortico-medullary differentiation (Figure 11).

The data were entered and stored in a spreadsheet (Excel, Microsoft). Statistical analysis was performed between the ultrasonographic renal parameters and serum creatinine levels with the aid of SPSS statistical software (version 17.0). Analysis was done using one way ANOVA and Pearson's correlation coefficient.

\section{RESULTS}

The age range of the patients was 19-85 yrs. with mean age of the patients was 54.32 years (Table I). There were $58 \%$ male cases and $46 \%$ were females with male:female ratio of 1.38:1 (Table II). The most common known cause of CKD in these patients was diabetes mellitus seen in 32 cases (32\%) followed by hypertension in 18 cases (18\%), diabetes and hypertension together in $5 \%$ of the cases. In $2 \%$ of cases, the cause was HIV associated nephropathy. No provisional cause was made in 43 cases (43\%) at the time of scanning (Table III).

The kidneys were small in size in $35 \%$ of the cases, the difference in size between right and left kidneys was more than $2 \mathrm{~cm}$ in $4 \%$ of the cases and the kidneys were enlarged in $3 \%$ of the cases. In $62 \%$ of cases, the kidneys were of normal size. The average kidney length measured in the present study was $8.69 \mathrm{~cm}$ (Range, 6.6-15.45 cm; $\mathrm{SD}=1.35 \mathrm{~cm}$ ).

The average parenchymal thickness of $1.7 \mathrm{~cm}$ was seen in $75 \%$ of the cases, reduced in $18 \%$ of the cases and in $7 \%$ of the cases the cortico-medullary differentiation was lost. Cortical thickness could not be assessed in 16 patients, as the renal pyramids could not be identified on USG (Table IV). The mean parenchymal thickness obtained in the present study was $1.77 \mathrm{~cm}$ (Range $1-2.35 \mathrm{cms}$; $\mathrm{SD}=0.3 \mathrm{~cm}$ ). The mean cortical thickness in our study was found to be $8.5 \mathrm{~mm}$ (Range $5.2 \mathrm{~mm}$ - $12.8 \mathrm{~mm}$; SD = $1.63 \mathrm{~mm}$ ) (Table IV).

The increased renal cortical echogenicity was reported in all the patients with CKD. Grade 1 increased echogenicity in $35(35 \%)$ cases, Grade 2 in $42(42 \%)$ cases, Grade 3 in 16 (16\%) cases and Grade 4 in 7 (7\%) cases. Corticomedullary differentiation was maintained in $77 \%$ of the cases, poorly maintained in $16 \%$ of the cases and it was lost in $7 \%$ of the cases (Table V). The mean serum creatinine values were 2.87 $\mathrm{mg} / \mathrm{dL}$ for Grade 1 echogenicity (Range 1.8 - $5.6 \mathrm{mg} / \mathrm{dL}$; $\mathrm{SD}=0.81$ ), $3.26 \mathrm{mg} / \mathrm{dL}$ for Grade 2 echogenicity (Range 1.6 $6.1 \mathrm{mg} / \mathrm{dL}$; SD=1.09), $4.3 \mathrm{mg} / \mathrm{dL}$ for Grade 3 echogenicity (Range 2.7 - $7.5 \mathrm{mg} / \mathrm{dL} ; \mathrm{SD}=1.58$ ) and $5.81 \mathrm{mg} / \mathrm{dL}$ for Grade 4 echogenicity (Range 3.6 - 9.5 mg/dL; SD=5.81) (Table VI).

The present study showed a statistically significant correlation between serum creatinine and the grade of echogenicity $(p=<0.001)$. (Table VI, Figure 1). The present 
study did not show any statistically significant correlation between serum creatinine values and renal length $(\mathrm{r}=0.096$; $\mathrm{p}=0.343)$, parenchymal thickness $(\mathrm{r}=-0.048$; $\mathrm{p}$ 0.649) or cortical thickness ( $\mathrm{r}=0.059$; $\mathrm{p}=0.577$ ).

(Table VII, Figures 2, 3, 4). Most common associated findings included renal cysts (09\%) followed by pleural effusion (08\%), renal calculi with or without hydronephrosis (07\%) and ascites (05\%). (Table VIII).

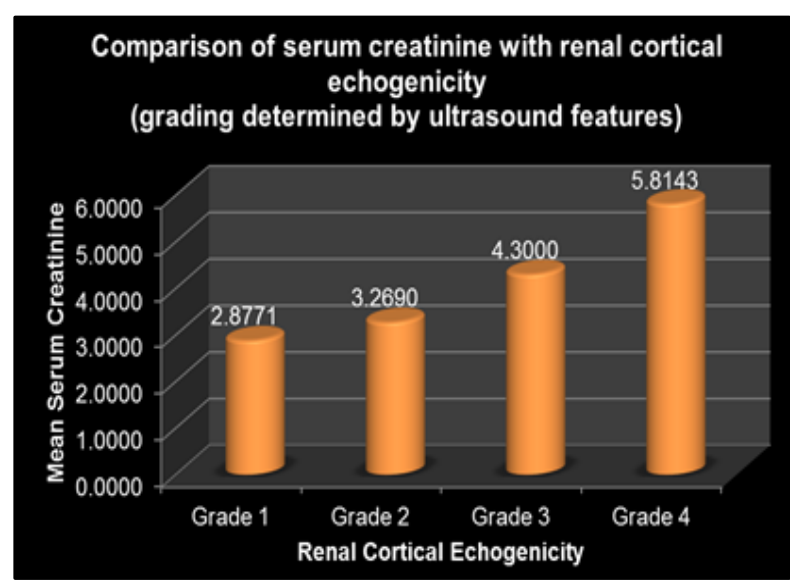

Fig. 1: Bar Diagram Showing the Relationship between Renal Cortical Echogenicity and Mean Serum Creatinine Levels from Grade 1-4. It shows as the Renal Cortical Echogenicity Increased, the Mean Serum Creatinine Levels Also Increased

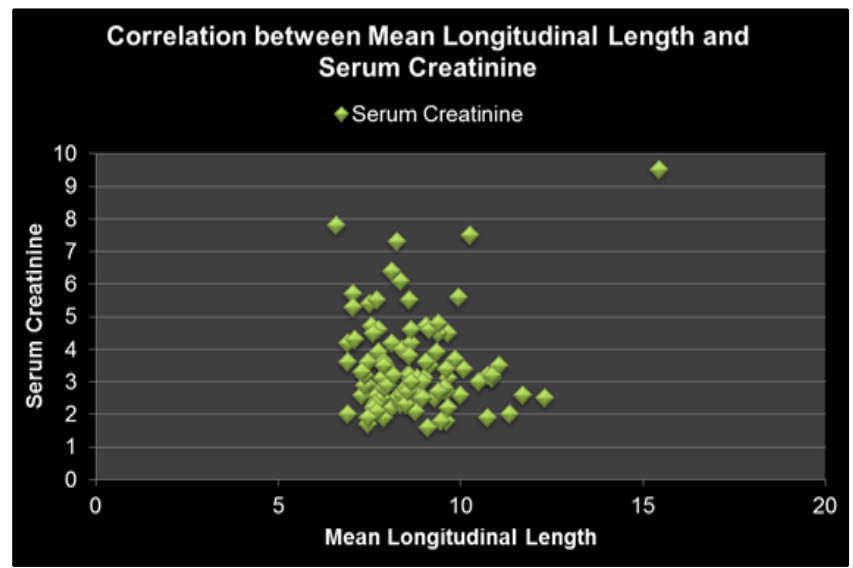

Fig. 2: Scatter Diagram Showing the Relationship between Mean Renal Longitudinal Lengths and Serum Creatinine Levels - No Correlation was Observed between the Two Variables

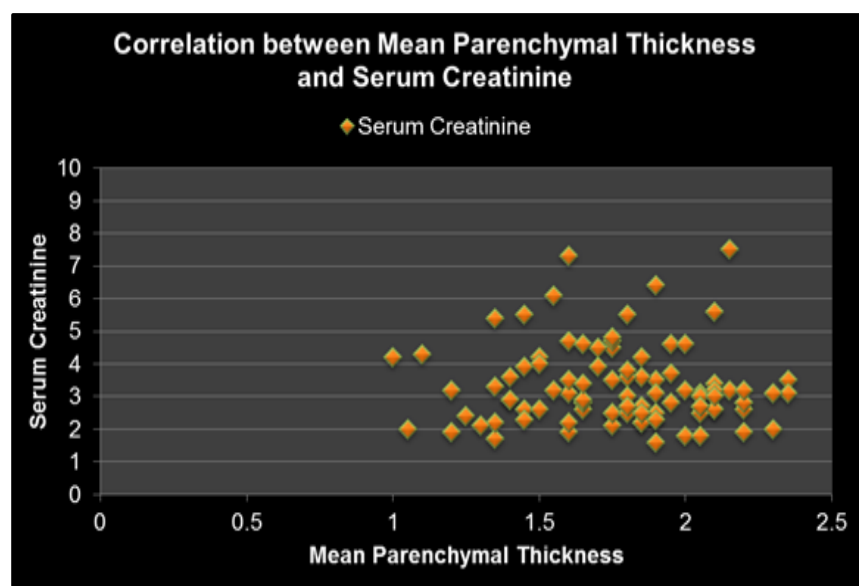

Fig. 3: Scatter Diagram Showing the Relationship between the Mean Parenchymal Thickness and Serum Creatinine Levels - No Correlation was Observed between the Two Variables

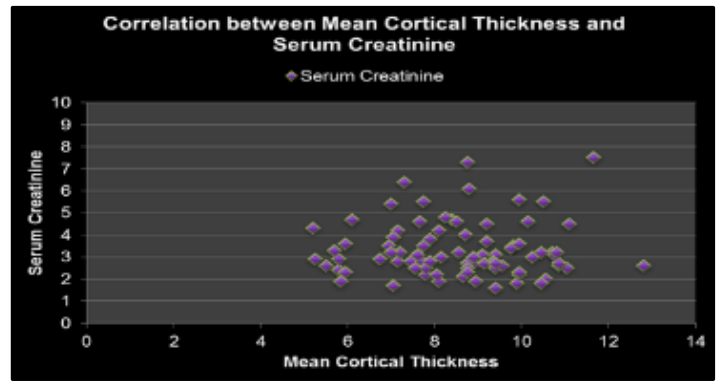

Fig. 4: Scatter Diagram Showing the Relationship between Mean Cortical Thickness and Serum Creatinine Levels - No Correlation was Observed between the Two Variables

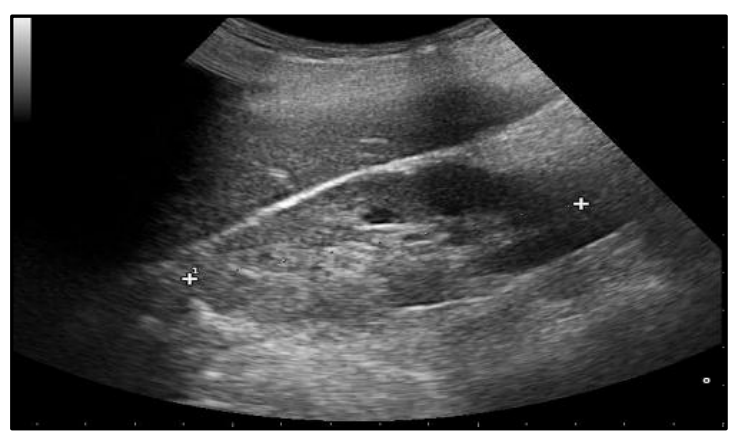

Fig. 5: Ultrasound of the Abdomen Showing Longitudinal Section of the Right Kidney with Renal Length Being Measured at the Extreme Pole to Pole Distance

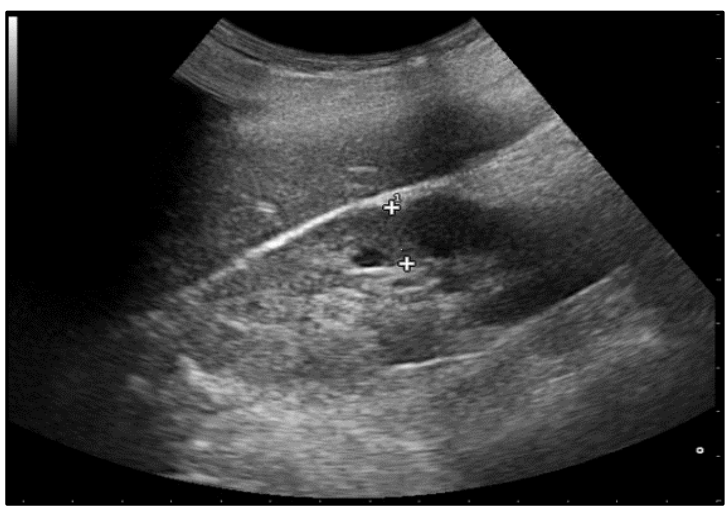

Fig. 6: Ultrasound of Abdomen Showing Longitudinal Section of the Right Kidney with the Normal Parenchymal Thickness Being Measured from the Central Sinus Fat up to the Maximum Convex Border

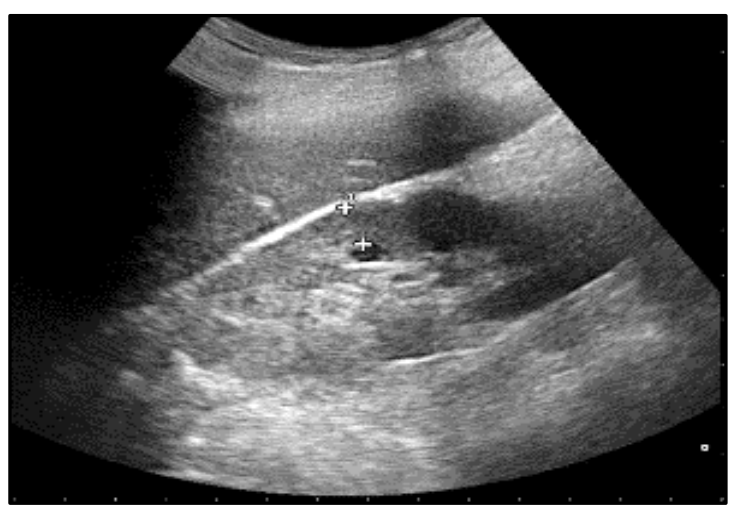

Fig. 7: Ultrasound of Abdomen Showing Longitudinal Section of the Right Kidney with Cortical Thickness Being Measured from the Renal Pyramid up to the Renal Capsule 


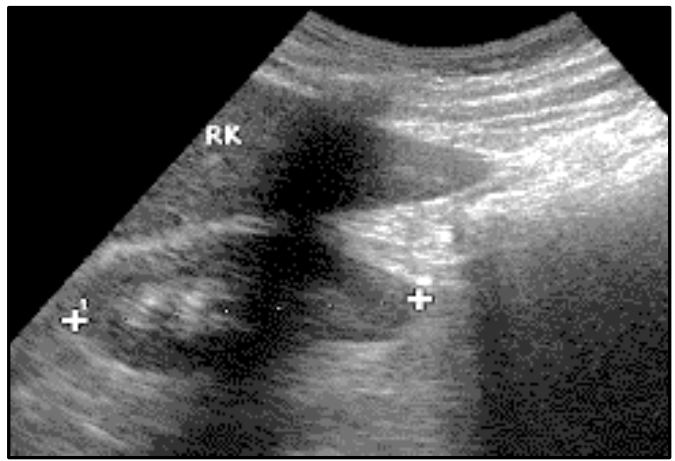

Fig. 8: Ultrasound of Abdomen Showing Longitudinal Section of the Right Kidney with its Echogenicity Equal to that of Liver and Maintained Cortico-Medullary Differentiation (Grade-1 Increased Echogenicity)

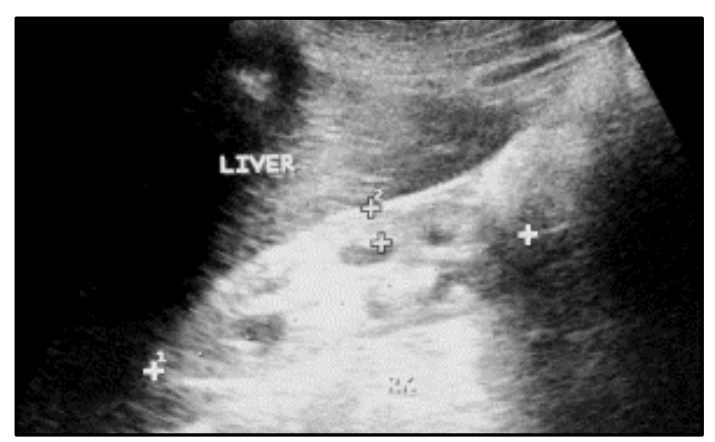

Fig. 9: Ultrasound of Abdomen Showing Longitudinal Section of the Right Kidney with its Echogenicity Greater Than that of Liver and Well-Maintained Corticomedullary Differentiation (Grade-2 Increased Echogenicity)

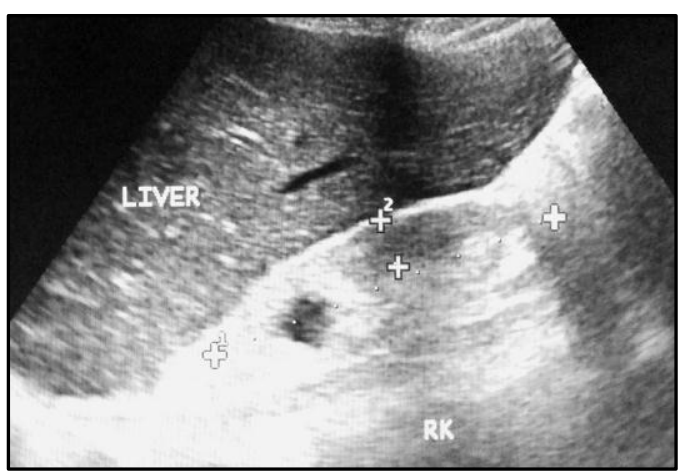

Fig. 10: Ultrasound of Abdomen Showing Longitudinal Sections of the Right Kidney (Marked as RK) with its Echogenicity Greater Than that of Liver and Poorly Maintained Cortico-Medullary differentiation (Grade 3 Increased Echogenicity)

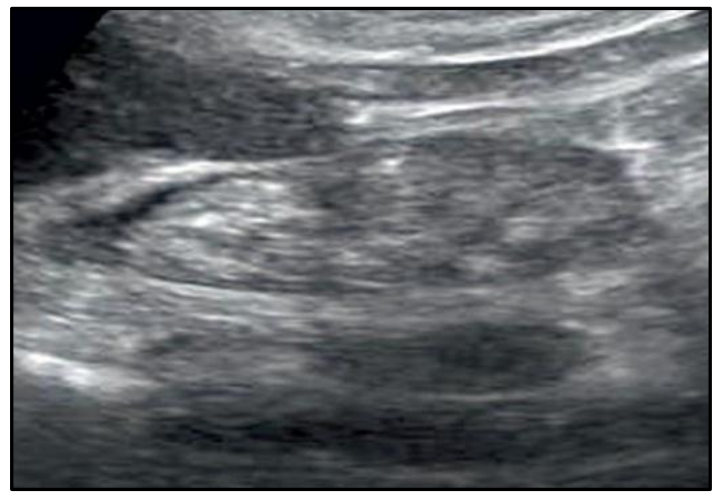

Fig. 11: Ultrasound of Abdomen Showing Longitudinal Sections of the Right Kidney with its Echogenicity Greater Than that of Liver and Loss of Cortico-Medullary Differentiation (Grade 4 Increased Echogenicity)
Table 1: Shows that the most frequent age group of patients with CKD was 51-60 yrs. (33\%) followed by 41-50 yrs. (31\%) with age group $81-90$ years $(1 \%)$ of the cases. The mean age was $54.32 \pm 12.25$ years.

\begin{tabular}{|c|c|c|}
\hline Age Range (In Years) & No. of Cases & Percentage \\
\hline $18-30$ & 03 & $03 \%$ \\
\hline $31-40$ & 08 & $08 \%$ \\
\hline $41-50$ & 31 & $31 \%$ \\
\hline $51-60$ & 33 & $33 \%$ \\
\hline $61-70$ & 16 & $16 \%$ \\
\hline $71-80$ & 09 & $09 \%$ \\
\hline $81-90$ & 01 & $01 \%$ \\
\hline Total & $\mathbf{1 0 0}$ & $\mathbf{1 0 0 \%}$ \\
\hline \multicolumn{3}{|l}{} \\
\hline \multicolumn{2}{|l}{} \\
\hline
\end{tabular}

Table 2: Shows that males were more commonly affected by chronic renal disease, $58 \%$ cases as compared to females with $42 \%$ cases. The male:female ratio was 1.38 .

\begin{tabular}{|c|c|c|}
\hline Gender & No. of Cases & Percentage \\
\hline Male & 58 & $58 \%$ \\
\hline Female & 42 & $42 \%$ \\
\hline \multicolumn{2}{|c|}{ Table 2: Gender Distribution of Cases } \\
with Chronic Kidney Disease \\
\hline
\end{tabular}

Table 3: Shows that in $43 \%$ of cases, no underlying cause of CKD was established. The single most common cause of CKD clinically was diabetes alone in 33\% cases followed by hypertension alone in $17 \%$ cases, $5 \%$ cases had co-existing diabetes and hypertension combined and in $2 \%$ cases had HIV associated nephropathy.

\begin{tabular}{|c|c|c|}
\hline Cause of CKD & No. of Cases & Percentage \\
\hline $\begin{array}{c}\text { Underlying cause of CKD } \\
\text { not established }\end{array}$ & 43 & $43 \%$ \\
\hline Diabetes & 32 & $32 \%$ \\
\hline Hypertension & 18 & $18 \%$ \\
\hline $\begin{array}{c}\text { Diabetes and } \\
\text { Hypertension } \\
\text { Combined }\end{array}$ & 05 & $05 \%$ \\
\hline HIV & 02 & $02 \%$ \\
\hline Table 3: Provisional Clinical Causes of Chronic Kidney Disease \\
\hline \multicolumn{2}{|c}{}
\end{tabular}

Table 4: Shows that there was a significant difference in size of right and left kidneys in $96 \%$ cases and only $4 \%$ cases showed difference in size $>2 \mathrm{~cm}$. Bilateral renal size was reduced in $35 \%$ cases, enlarged in 3\% cases with normal sized kidneys in $53 \%$ cases. The average parenchymal thickness was $75 \%$ of the cases, which was normal while it was reduced in $18 \%$ of the cases. However, in $7 \%$ cases it could not be assessed as the cortico-medullary differentiation was lost. Cortical thickness was reduced in $84 \%$ patients and in $16 \%$ cases could not be assessed as the renal pyramids could not be identified on sonography.

\begin{tabular}{|c|c|c|c|}
\hline \multicolumn{4}{|c|}{ Sonography Renal Findings } \\
\hline \multicolumn{2}{|c|}{ Renal } \\
Parameters & $\begin{array}{c}\text { No. of } \\
\text { Cases }\end{array}$ & Percentage \\
\hline Renal Size & $\begin{array}{c}\text { Not Significant } \\
(<2 \mathrm{~cm})\end{array}$ & 96 & $96 \%$ \\
$\begin{array}{c}\text { Difference } \\
\text { (Right vs. Left) }\end{array}$ & $\begin{array}{c}\text { Significant } \\
(>2 \mathrm{~cm})\end{array}$ & 04 & $04 \%$ \\
\hline & Enlarged & & \\
Average Renal & $(>12 \mathrm{~cm})$ & 03 & $03 \%$ \\
Length & Normal & 62 & $62 \%$ \\
$(8.69 \mathrm{~cm})$ & $(8-12 \mathrm{~cm})$ & 35 & $35 \%$ \\
& Small $(<8 \mathrm{~cm})$ & & \\
\hline
\end{tabular}




\begin{tabular}{|c|c|c|c|}
\hline $\begin{array}{c}\text { Average } \\
\text { Parenchymal } \\
\text { Thickness } \\
(1.77 \mathrm{~cm})\end{array}$ & $\begin{array}{c}\text { Normal } \\
(\geq 15 \mathrm{~mm}) \\
\text { Reduced } \\
(<15 \mathrm{~mm}) \\
\text { Could not be } \\
\text { assessed }\end{array}$ & $\begin{array}{l}75 \\
18 \\
07\end{array}$ & $\begin{array}{l}75 \% \\
18 \% \\
07 \%\end{array}$ \\
\hline $\begin{array}{l}\text { Average } \\
\text { Cortical } \\
\text { Thickness } \\
(8.5 \mathrm{~mm})\end{array}$ & $\begin{array}{c}\text { Reduced } \\
\text { Could not be } \\
\text { assessed }\end{array}$ & $\begin{array}{l}84 \\
16\end{array}$ & $\begin{array}{l}84 \% \\
16 \%\end{array}$ \\
\hline \multicolumn{4}{|c|}{$\begin{array}{c}\text { Table 4: USG Findings of Renal Size Parameters } \\
\text { with Chronic Kidney Disease }\end{array}$} \\
\hline
\end{tabular}

Table 5: Shows that 35 cases had Grade 1 increased echogenicity (35\%), 42 cases had Grade 2 increased echogenicity (42\%), 16 cases had Grade 3 increased echogenicity (16\%) and 7 cases had Grade 4 increased echogenicity (7\%). (In case of difference in the echogenicity, higher grade of the kidney was taken into account). Corticomedullary differentiation was maintained in $77 \%$ of the cases, poorly maintained in $16 \%$ of the cases and it was lost with $7 \%$ of the cases.

\begin{tabular}{|c|c|c|c|}
\hline \multicolumn{2}{|c|}{ Renal Changes } & $\begin{array}{c}\text { No. of } \\
\text { Cases }\end{array}$ & Percentage \\
\hline Bilateral & Similar & 96 & $96 \%$ \\
Echogenicity & Different & 04 & $04 \%$ \\
\hline & Grade 1 & 35 & $35 \%$ \\
Grade of & Grade 2 & 42 & $42 \%$ \\
Echogenicity & Grade 3 & 16 & $16 \%$ \\
& Grade 4 & 07 & $07 \%$ \\
\hline \multirow{2}{*}{ Corticomedullary } & Maintained & 77 & $77 \%$ \\
Differentiation & Poorly & 16 & $16 \%$ \\
& Maintained & 07 & $07 \%$ \\
\hline
\end{tabular}

Table 5: USG Findings Related to Echogenicity and CorticoMedullary Differentiation in Cases with Chronic Kidney Disease $(N=100)$

Table 6: Shows that the mean serum creatinine values in the present study were $2.87 \mathrm{mg} / \mathrm{dL}$ for Grade 1 echogenicity (range 1.8-5.6 mg/dL; SD=0.81), $3.26 \mathrm{mg} / \mathrm{dL}$ for Grade 2 echogenicity (range 1.6-6.1 mg/dL; SD=1.09), 4.3 $\mathrm{mg} / \mathrm{dL}$ for Grade 3 echogenicity (range $2.7-7.5 \mathrm{mg} / \mathrm{dL}$; $\mathrm{SD}=1.58$ ) and $5.81 \mathrm{mg} / \mathrm{dL}$ for Grade 4 echogenicity (range, 3.6-9.5 mg/dL; $\mathrm{SD}=2.11$ ). A statistically significant correlation between serum creatinine and the grade of echogenicity $(\mathrm{p}=<0.001)$ was observed.

\begin{tabular}{|c|c|c|c|c|c|c|c|}
\hline \multicolumn{8}{|c|}{ SERUM CREATININE } \\
\hline $\begin{array}{c}\text { Renal } \\
\text { cortical } \\
\text { echogenicity }\end{array}$ & $\mathrm{N}$ & Mean & SD & Min & Max & $\begin{array}{c}\text { F } \\
\text { value }\end{array}$ & $\begin{array}{c}\mathrm{P} \\
\text { value }\end{array}$ \\
\hline Grade 1 & 35 & 2.8771 & 0.81062 & 1.80 & 5.60 & \multirow{5}{*}{14.927} & \multirow{5}{*}{$<0.001$} \\
\hline Grade 2 & 42 & 3.2690 & 1.09911 & 1.60 & 6.10 & & \\
\hline Grade 3 & 16 & 4.3000 & 1.58114 & 2.70 & 7.50 & & \\
\hline Grade 4 & 7 & 5.8143 & 2.11063 & 3.60 & 9.50 & & \\
\hline Total & 100 & 3.4750 & 1.41987 & 1.60 & 9.50 & & \\
\hline
\end{tabular}

Table 7: Did not show any statistically significant correlation between serum creatinine values and renal length $(\mathrm{r}=0.096 ; \mathrm{p}=0.343)$, parenchymal thickness $(\mathrm{r}=-0.048$; $\mathrm{p}=0.649$ ) or cortical thickness $(\mathrm{r}=0.026 ; \mathrm{p}=0.813)$.

\begin{tabular}{|c|c|c|c|}
\hline \multicolumn{4}{|c|}{ Statistical Correlations } \\
\hline \multirow{2}{*}{$\begin{array}{c}\text { Renal } \\
\text { Parameters }\end{array}$} & \multicolumn{3}{|c|}{ Serum Creatinine (mg/dL) } \\
\hline & $\begin{array}{c}\text { Pearson's } \\
\text { Correlation } \\
\text { Coefficient }\end{array}$ & $\begin{array}{c}P \\
\text { values }\end{array}$ & $\mathbf{N}$ \\
\hline $\begin{array}{l}\text { Mean longitudinal } \\
\text { length (In cm) }\end{array}$ & 0.096 & 0.343 & 100 \\
\hline $\begin{array}{l}\text { Mean parenchymal } \\
\text { thickness }(\mathrm{In} \mathrm{cm})\end{array}$ & -0.048 & 0.649 & 93 \\
\hline $\begin{array}{c}\text { Mean cortical } \\
\text { thickness (In mm) }\end{array}$ & 0.026 & 0.813 & 84 \\
\hline \multicolumn{4}{|c|}{$\begin{array}{l}\text { Table 7: Statistical Correlations Between Serum } \\
\text { Creatinine and Mean Longitudinal Length, Mean } \\
\text { Parenchymal Thickness and Mean Cortical Thickness }\end{array}$} \\
\hline
\end{tabular}

Table 8: Shows that renal cysts were the most common associated finding seen in $09 \%$ of the cases followed by pleural effusion (08\%), renal calculi with or without hydronephrosis (07\%), ascites (05\%), prominent intrahepatic veins $(01 \%)$, hepatic cysts $(01 \%)$, and GB wall oedema (01\%).

\begin{tabular}{|c|c|c|}
\hline $\begin{array}{c}\text { Associated } \\
\text { USG Findings }\end{array}$ & $\begin{array}{c}\text { No. of } \\
\text { Cases }\end{array}$ & Percentage \\
\hline Renal Cysts & 09 & $09 \%$ \\
\hline Pleural Effusion & 08 & $08 \%$ \\
\hline $\begin{array}{c}\text { Renal calculi with or without } \\
\text { hydronephrosis }\end{array}$ & 07 & $07 \%$ \\
\hline Ascites & 05 & $05 \%$ \\
\hline Prominent intrahepatic veins & 01 & $01 \%$ \\
\hline Hepatic Cysts & 01 & $01 \%$ \\
\hline GB wall oedema & 01 & $01 \%$ \\
\hline $\begin{array}{c}\text { Table 8: Associated Findings on Ultrasound } \\
\text { with Chronic Kidney Disease (N=100) }\end{array}$ \\
\hline
\end{tabular}




\section{DISCUSSION}

The burden of CRF has increased exponentially and is consuming the resources of both developed and developing economies and efforts to reduce the cost of managing this dreadful disease are always welcomed. This study was geared towards looking for a simpler method of determining the functional capacity of the kidneys in CKD and eliminating (If possible) the need for double determination of GFR using serum biochemistry, particularly in resource-poor settings. The ultrasound machine is quite cheaply and widely available and provides real-time information on the renal measurements and echogenicity particularly in resource poor settings. $^{8}$

Renal length is measured as the longest diameter obtained on a posterior oblique image with a lower limit of normality generally indicated as $9 \mathrm{~cm}$. According to Fiorini and Barozzi, renal length under $8 \mathrm{~cm}$ is definitely reduced and should be attributed to chronic renal failure, whereas a length between 8 and $9 \mathrm{~cm}$ should always be correlated to the patient's phenotype, particularly the height. ${ }^{9}$ Hence, a lower limit of $8 \mathrm{~cm}$ was selected for the present study. According to O'Neill, the useful upper limit of the normal range for kidney length is said to be $12 \mathrm{~cm}$. Also, a threshold of $2 \mathrm{~cm}$ is considered reasonable for diagnosing pathological size discrepancy between the two kidneys. ${ }^{10}$ Kidneys measuring more than $12 \mathrm{~cm}$ in length were considered enlarged in the present study.

Kidney length was affected in $38 \%$ of the patients - the kidneys were small in size in $35 \%$ of the cases and the kidneys were enlarged in $3 \%$ of the cases. In the remaining $62 \%$ of cases, the kidneys were of normal size. The pathological discrepancy in size $(>2 \mathrm{~cm})$ was seen in $4 \%$ of the cases in the present study. Of the 3 cases having enlarged kidney sizes, 2 cases were diabetic and 1 case had Adult Polycystic Kidney Disease (APKD), thus explaining the enlarged kidney sizes in CKD, as nephromegaly is common in both DM and APKD. ${ }^{11,12}$

Of the 4 cases having size discrepancies 1 case had unilateral hydronephrosis, 1 case was hypertensive with unilateral small kidney with the clinical suspicion of renal artery stenosis, 1 case had clinical suspicion and sonographic features of pyelonephritis in a diabetic and the remaining case had adult polycystic kidney disease having irregular enlargement of the two kidneys due to numerous cysts, thus explaining the difference in the sizes. In the study conducted by Moccia et al, the kidney size was affected in $57 \%$ of the cases having chronic renal disease, of which 7 cases had size discrepancy. ${ }^{13}$ The mean renal length measured in the present study was $8.69 \mathrm{~cm}$ (Range $6.6-15.45 \mathrm{~cm}$; SD=1.35 $\mathrm{cm})$. This correlated well with the findings of Yamashita et al, in which the average renal length was $9.5 \mathrm{~cm}$ in CKD patients (Range $6.99-13 \mathrm{~cm}$; $\mathrm{SD}=1.25 \mathrm{~cm}$ ). ${ }^{6}$

Normal parenchymal thickness ranges from $1.5-2 \mathrm{~cm} .{ }^{9}$ The mean parenchymal thickness obtained in the present study was $1.77 \mathrm{~cm}$ (Range $1-2.35 \mathrm{cms}$; SD=0.3 cm). The average parenchymal thickness was normal in $75 \%$ of the cases. In $18 \%$ of the cases it was reduced and in $7 \%$ of the cases it could not be assessed as the cortico-medullary differentiation was lost. These findings correlated well with those of Moghazi et al who found the mean parenchymal thickness to be $1.71 \mathrm{~cm}$ (Range, $0.7-3.3 \mathrm{~cm}$ ). ${ }^{14}$
There is no established normal range of cortical thickness. A normal range of 8 to $11.5 \mathrm{~mm}$ was reported in a small study of transplant donors by Raj et al. ${ }^{15}$ However, ElReshaid et al stated that cortical thickness values up to $6 \mathrm{~mm}$ are also considered to be normal.16 The mean cortical thickness in our study was found to be $8.5 \mathrm{~mm}$ (Range 5.2 $\mathrm{mm}-12.8 \mathrm{~mm}$; SD=1.63 mm). Cortical thickness could not be assessed in 16 patients as the renal pyramids could not be identified on USG. The findings were closely consistent with those of Yamashita et al who found the mean cortical thickness to be $7.1 \mathrm{~mm}$ in their cases. ${ }^{6}$ Beland et al reported a mean cortical thickness of $5.9 \mathrm{~mm}$ in CKD patients in their study. ${ }^{17}$

Raised renal cortical echogenicity was reported in all the patients with CKD in this present study. Only 4 cases had difference in the echogenicities of the two kidneys, remaining 96 cases had similar echogenicity changes in both the kidneys suggesting that echogenicity changes occur in CKD patients bilaterally and symmetrically. Paivansalo et al also reported that an echogenic cortex was the most common abnormality detected. ${ }^{18}$ In the present study, echogenicity was further graded according to the classification proposed by Siddappa et al. ${ }^{19} 35$ cases had Grade 1 echogenicity (35\%), 42 cases had Grade 2 echogenicity (42\%), 16 cases had Grade 3 echogenicity (16\%) and 7 cases had Grade 4 echogenicity (7\%). Thus, Grade 2 echogenicity had maximum number of cases. These findings were slightly different from those of Siddappa et al, who found Grade 1 echogenicity to be the largest group with $48.3 \%$ of the cases in it. ${ }^{19}$ Also, in the present study, cortico-medullary differentiation was maintained in $77 \%$ of the cases, poorly maintained in $16 \%$ of the cases and it was lost in $7 \%$ of the cases. This finding closely correlated well with those of Siddappa et al, who had $83.3 \%$ of cases with maintained cortico-medullary differentiation, $11.7 \%$ with poorly maintained corticomedullary differentiation and in $5 \%$ of the cases the corticomedullary differentiation was lost. 19

The mean serum creatinine values in the present study were $2.87 \mathrm{mg} / \mathrm{dL}$ for Grade 1 echogenicity (Range 1.8 - 5.6 $\mathrm{mg} / \mathrm{dL} ; \mathrm{SD}=0.81), 3.26 \mathrm{mg} / \mathrm{dL}$ for Grade 2 echogenicity (Range 1.6 - $6.1 \mathrm{mg} / \mathrm{dL} ; \mathrm{SD}=1.09$ ), $4.3 \mathrm{mg} / \mathrm{dL}$ for Grade 3 echogenicity (Range 2.7 - $7.5 \mathrm{mg} / \mathrm{dL} ; \mathrm{SD}=1.58$ ) and 5.81 $\mathrm{mg} / \mathrm{dL}$ for Grade 4 echogenicity (Range 3.6 - $9.5 \mathrm{mg} / \mathrm{dL}$; $\mathrm{SD}=2.11$ ). The present study showed a statistically significant correlation between serum creatinine and the grade of echogenicity $(p=<0.001)$. This finding was consistent with the findings of Siddappa et al who also noted a statistically significant correlation between these two parameters $(\mathrm{p}=0.004) .{ }^{19}$ Ibinaiye et al had a similar finding $(\mathrm{r}=0.9) .{ }^{20}$

This correlation can be explained by the research findings of Rosenfield and Siegel, who documented that the echogenicity of the kidneys had a good correlation with the severity of the interstitial disease on biopsy. Focal interstitial changes tend to produce a minimal increase in cortical echogenicity, while diffuse scarring produces a greater increase in echogenicity. ${ }^{21}$ Moghazi et al also supported this finding by stating that renal echogenicity had the strongest correlation with histological parameters (Glomerular Sclerosis, Tubular Atrophy, Interstitial Fibrosis and Interstitial Inflammation). ${ }^{14}$ Hricak et al showed a statistically significant positive correlation between cortical echogenicity and the severity of global sclerosis, focal tubular atrophy, the 
number of hyaline casts per glomerulus and focal leucocytic infiltration. ${ }^{22}$

Renal length has traditionally been considered a surrogate marker of renal function. ${ }^{8}$ in the present study; the renal length did not show statistically significant correlation with the serum creatinine values $(r=0.096 ; p=0.343)$. In this context, our finding was consistent with those of Moccia et al, who also did not find any significant correlation between renal length and serum creatinine levels. ${ }^{13}$ This finding is further supported by the research of Van Den Noortgate et al who confirmed that renal length has a low specificity in predicting renal impairment. In clinical practice, serum creatinine and calculated creatinine clearance is most useful in predicting renal impairment. They also mentioned that a normal renal length in the elderly, however, can help exclude renal impairment. ${ }^{23}$ Our study contradicted this finding, as we did have elderly patients with normal renal length having impaired renal functions.

In the present study, the parenchymal thickness did not show statistically significant correlation with the serum creatinine values $(r=-0.048 ; p=0.649)$. This finding was consistent with those of Yamashita et al, who found that parenchymal thickness had non-significant correlation with the renal function impairment. They also stated that the measurement of the thickness of the renal parenchyma, which is still widely used in the clinical practice to infer some chronic nephropathies should be discouraged, since it showed no statistical correlation with renal function impairment and therefore it is useless in this context. ${ }^{6}$ Our present study further confirmed this finding.

In the present study, the cortical thickness did not show statistically significant correlation with the serum creatinine values ( $\mathrm{r}=0.059 ; \mathrm{p}=0.577$ ). In this context, our finding was consistent with those of Siddappa et al who did not find a statistically significant correlation between cortical thickness and serum creatinine levels and reported a p value of 0.656 for these two parameters. ${ }^{19}$

In this context, our finding contradicted those of Beland et $\mathrm{al}^{17}$ and Yamashita et $\mathrm{al}^{6}$ who reported that cortical thickness had statistically significant correlation with renal function impairment. Moghazi et al had also shown that cortical thickness had no significant correlation with the histological parameters like glomerular sclerosis, tubular atrophy, interstitial fibrosis and interstitial inflammation. ${ }^{14}$

The statistically insignificant correlations of renal measurements with serum creatinine levels in the present study can also be related by the facts that kidney length varies with body height in both adults and children.10 The renal length has also been showed to vary with weight and BMI of the person. ${ }^{16}$ Although ischaemic nephropathy causes cortical thinning, renal hypertrophy in diabetic nephropathy affects all components, so that the kidney maintains its shape and architecture in the early phase. Due to the incipient nephromegaly, the diabetic kidney often looks bigger and 'Better' than the kidney with the same level of chronic, irreversible renal failure caused by other chronic renal diseases such as other glomerular diseases, hypertensive nephropathy or tubulointerstitial diseases.

Consequently, in the case of diabetic nephropathy, it is often difficult to predict the irreversibility of renal failure solely on the basis of renal length or thickness of the parenchyma. Even in the phase of end-stage renal disease, the diabetic kidney can retain the size of a normal kidney. ${ }^{11}$ In the present study, ultrasound was able to diagnose the cause of chronic renal impairment due to renal calculi or polycystic kidney disease with certainty in all the 8 cases that were studied. In this context our study supports the findings of Moccia et al, stated that the exclusion of obstructive uropathy or polycystic disease as the cause of renal failure had been always possible with USG. An ultrasound is usually performed in renal failure to exclude the obstructive uropathy. ${ }^{13}$

This study had a few limitations. Serum creatinine levels were used as a marker of renal function in the present study. Serum creatinine concentration is widely interpreted as a measure of the Glomerular Filtration Rate (GFR) and is used as an index of renal function in clinical practice. ${ }^{24}$ It is the most widely used index of renal function. ${ }^{23}$ However, estimates of GFR measured by either CG or MDRD equations are the best overall indices of the level of kidney function. ${ }^{25}$ More studies relating these ultrasonographic parameters to the estimates of GFR should be welcomed. Also, since ultrasonography is an operator dependent modality, measurements like cortical thickness has been shown to have inter-observer and intra-observer variations with poor reproducibility when comparing repeated measurements.

Despite its limitations, the present study has shown a good correlation of renal cortical echogenicity with serum creatinine levels. The renal cortical echogenicity has its advantages of being irreversible compared to serum creatinine levels, which improve with renal replacement therapies like haemodialysis and peritoneal dialysis. ${ }^{24}$ Also, quantification of echogenicity of the renal cortex relative to that of the liver has been shown to be reproducible with only little variability between different scanners and probes in previous studies. ${ }^{26}$

\section{REFERENCES}

1. Veerappan I, Abraham G. Chronic kidney disease: current status, challenges and management in India. Ch. 130, Sec. 17. apiindia.org/medicine_update 2013;p 593.

2. Agarwal SK, Srivastava RK. Chronic kidney disease in India: challenges and solutions. Nephron Clin Pract 2009;111(3):197-203.

3. Levey AS, Coresh J, Balk E, et al. National kidney foundation practice guidelines for chronic kidney disease: evaluation, classification, and stratification. Ann Intern Med 2003;139(2):137-47.

4. Emamian SA, Nielsen MB, Pedersen JF. Intraobserver and interobserver variations in sonographic measurements of kidney size in adult volunteers a comparison of linear measurements and volumetric estimates. Acta Radiol 1995;36(4):399-401.

5. Hergesell O, Felten H, Andrassy K, et al. Safety of ultrasound-guided percutaneous renal biopsyretrospective analysis of 1,090 consecutive cases. Nephrol Dial Transplant 1998;13(4):975-77.

6. Yamashita SR, Von Atzingen AC, Iared W, et al. Value of renal cortical thickness as a predictor of renal function impairment in chronic renal disease patients. Radiologia Brasileira 2015;48(1):12-6.

7. Duru OK, Vargas RB, Kermah D, et al. High prevalence of stage 3 chronic kidney disease in older adults despite normal serum creatinine. J Gen Intern Med 2008;24(1):86-92. 
8. Sanusi AA, Arogundade FA, Famurewa OC, et al. Relationship of ultrasonographically determined kidney volume with measured GFR, calculated creatinine clearance and other parameters in chronic kidney disease (CKD). Nephrol Dial Transplant 2009;24(5):1690-4.

9. Fiorini F, Barozzi L. The role of ultrasonography in the study of medical nephropathy. J Ultrasound 2007;10(4):161-7. doi:10.1016/j.jus.2007.09.001

10. O'Neill WC. Sonographic evaluation of renal failure. Am J Kidney Dis 2000;35(6):1021-38.

11. Buturovic J, Visnar-Perovic A. Ultrasonography in chronic renal failure. Eur J Radiol 2003;46(2):115-22.

12. Nicolau C, Torra R, Bardenas C, et al. Autosomal dominant polycystic kidney disease types 1 and 2: assessment of US sensitivity for diagnosis. Radiology 1999;213(1):273-6.

13. Moccia WA, Kaude JV, Wright PG, et al. Evaluation of chronic renal failure by digital gray-scale ultrasound. Urol Radiol 1980;2(1):1-7.

14. Moghazi S, Jones E, Schroepple J, et al. Correlation of renal histopathology with sonographic findings. Kidney Int 2005;67(4):1515-20.

15. Raj DSC, Hoisala R, Somiah S, et al. Quantitation of change in the medullary compartment in renal allograft by ultrasound. J Clin Ultrasound 1997;25(5):265-69.

16. El-Reshaid W, Abdul-Fattah H. Sonographic assessment of renal size in healthy adults. Med Princ Pract 2014;23(5):432-36.

17. Beland MD, Walle NL, Machan JT, et al. Renal cortical thickness measured at ultrasound: is it better than renal length as an indicator of renal function in chronic kidney disease? Am J Roentgenol 2010;195(2):W146-9.
18. Päivänsalo $M$, Huttunen K, Suramo I. Ultrasonographic findings in renal parenchymal diseases. Scand J Urol Nephrol 1985;19(2):119-23.

19. Siddappa JK, Singla S, Al Ameen M, et al. Correlation of ultrasonographic parameters with serum creatinine in chronic kidney disease. J Clin Imaging Sci 2013;3:28.

20. Ibinaiye PO, Garko SS, Ahmed A, et al. Relationship of ultrasound renal echogenicity, serum creatinine level and CD4 cell counts in patients with human immunodeficiency virus-associated nephropathy. Sub-Saharan Afr J Med 2014;1(4):191-7.

21. Rosenfield AT, Siegel NJ. Renal parenchymal disease: histopathologic ${ }^{-}$sonographic correlation. Am J Roentgenol 1981;137(4):793-8.

22. Hricak H, Cruz C, Romanski R, et al. Renal parenchymal disease: sonographic-histologic correlation. Radiology 1982;144(1):141-7.

23. Van Den Noortgate N, Velghe A, Petrovic M, et al. The role of ultrasonography in the assessment of renal function in the elderly. J Nephrol 2003;16(5):658-62.

24. Perrone RD, Madias NE, Levey AS. Serum creatinine as an index of renal function: new insights into old concepts. Clin Chem 1992;38(10):1933-53.

25. National Kidney Foundation. K/DOQI clinical practice guidelines for chronic kidney disease: evaluation, classification and stratification. Am J Kidney Dis 2002;39(2 suppl 1):S1-266.

26. Manley JA, O'Neill WC. How echogenic is echogenic? quantitative acoustics of the renal cortex. Am J Kidney Dis 2001;37(4):706-11. 